\title{
Student teachers' positioning with regard to their key learning experiences in the first practicum
}

\author{
Experiencias clave de aprendizaje y posicionamiento de los estudiantes de \\ magisterio en su primer Prácticum
}

\author{
Mireya Giralt-Romeu \\ Eva Liesa Hernández \\ Paula Mayoral Serrat \\ Ramon Llull University \\ Lorena Becerril Balín \\ Universitat Oberta de Catalunya
}

\begin{abstract}
This exploratory study consists of a description of which kind of key learning experiences student teachers' have to face during their first practicum in schools and how they positioned their selves in these situations. Twenty-seven second-year student teachers were interviewed. Five key learning experiences were identified: classroom instruction, socialization, conflicting between pre-existing conceptions and the reality, classroom management, and diversity. Two kinds of positions were adopted by them when they faced these experiences: I as a student and I as a teacher. They positioned as students when they focused their attention on observing educational practices and fully and unreservedly accepting their mentors' strategies and they positioned as teachers when they acted and made decisions with autonomy and applied the theoretical knowledge acquired. The difficulties students face in positioning themselves as teachers were found to relate to all the key learning experiences except for those connected to do with classroom instruction.
\end{abstract}

Keywords: Teacher training; Identity; Key learning experiences; I-position

\section{Resumen}

Este estudio exploratorio describe el tipo de experiencias clave de aprendizaje a las que se enfrentan los estudiantes docentes durante su primera práctica en las escuelas y cómo se posicionaron en estas situaciones. Veintisiete estudiantes de segundo año fueron entrevistados. Se identificaron cinco experiencias clave de aprendizaje: instrucción en el aula, socialización, conflicto entre las concepciones preexistentes y la realidad, gestión del aula e diversidad. Adoptaron dos tipos de posiciones ante las experiencias: yo como estudiante y yo como maestro/a. Se posicionaron como estudiantes cuando enfocaron su atención en observar las prácticas educativas, aceptando sin reservas las estrategias de sus mentores, y se posicionaron como maestros cuando actuaron y tomaron decisiones con autonomía y aplicaron el conocimiento teórico adquirido en los contextos universitarios. Los resultados muestran que las dificultades que enfrentan los estudiantes para posicionarse como maestros se relacionan con todas las experiencias clave de aprendizaje, excepto las relacionadas con la instrucción en el aula.

Palabras clave: Formación del profesorado; Identidad; Experiencias clave de aprendizaje; Posiciones del Yo 


\section{INTRODUCTION}

The past few decades have witnessed a great deal of new research into how teachers form their professional identities. Some of these studies have shown that student teachers' beliefs and biographies can play key roles in forming their professional identities as teachers (Beijaard, Meijer, \& Verloop, 2004). However, definitions of the construct of teachers' professional identity have developed and shifted over time, as have the ideas as to what contextual and personal factors expert an influence on this identity formation (Colliander, 2018). It is clear, though, that professional identity at least partially emerges from the spaces and activities of students' initial teacher training.

Previous research has shown the great influence of the context of the Practicum in the formation of teachers' professional identity (Allen \& Wright, 2014; Körkkö, Kyrö-Ämmälä, \& Turunen, 2016). These studies emphasize the importance of Practicum as an opportunity for student teachers to test their previous conceptions about what it means to be a teacher and the educational theories they have learned against what really happens in the classroom. This friction usually appears during key learning experiences (Ahonen, Pyhältö, Pietarinen \& Soini, 2015) or critical incidents (Monereo, 2019; Sisson, 2016). However, less is known about how student teachers tend to position themselves with regard to learning experiences and how these learning experiences can help student teachers develop their professional identities as teachers.

This study aims to contribute to the existing literature and to explore how student teachers perceive the learning experiences faced during their first practicum and how they position themselves as they face these experiences.

\section{Identity as a dialogical construction: student teachers' positioning}

Dialogical self theory (DST) helps shed light on how personal and social positions are coordinated at an intra-psychological level. Positions are not isolated entities fixed somewhere within the space of the self. Instead, they interact with each other and can form new combinations that are more than the sum of their parts (Hermans, 2001; Hermans \& Hermans-Konopka, 2010).

The self is as a society of 'I-positions'. An I-position can be considered defined as a "voiced" position (Akkerman \& Meijer, 2011). The term "l" refers to a subject-position, a first-person perspective from which the world and the self are perceived, experienced, and evaluated. Each I-position adopted by a subject can be considered an expression of his/her personal identity (Raggatt, 2015).

From this perspective, identity is individual but, at the same time, it is socially constructed over time through interactions with others, because it emerges 
from intrinsic contact with the social environment (Hermans \& Gieser, 2012). On the individual level, the self is considered a sense-making system that is closely linked to the activity of creating meaning for the world. As a subjective space of negotiation, the dialogical self allows people to understand, explain and give meaning to themselves and the world, creating this meaning by interacting with themselves, significant others and the world (Linell, 2009).

A teacher's identity is a type of professional position, in that it takes shape through ongoing shifts between different I-positions. At the same time, however, this identity is continuous, in that the teacher maintains a sense of self that transcends these changes, a self that is recognizable over time (Meijers \& Hermans, 2018).

Some authors have defined teachers' identity as "being someone who teach as an ongoing process of negotiating and interrelating multiple I-positions in such a way that a more or less coherent and consistent sense of self is maintained throughout various participations and self-investment in one's (working) life" (Akkerman \& Meijer, 2011, p. 315). Although these authors questioned the usefulness of the popular distinction between 'personal' and 'professional' positions according to the DST, there is still some debate about how these two kinds of positions enter into dialogue with one another during the process of construction of teacher's identities (e.g., Leijen \& Kullasepp, 2013a, 2013b; Leijen, Kullasepp, \& Ots, 2013; Toompalu, Leijen, \& Kullasepp, 2016). This process is called positioning, and it consists of positioning oneself in time and space (Meijer \& Hermans, 2018). In addition, we may be repositioned by the signs and messages communicated to us by others.

Janet Alsup (2006) has shown the importance of coherence, or internal agreement, between different identity positions when entering the teaching profession. One mechanism that allows for dialogue between positions is 'coalition'. A coalition occurs when two or more positions are distinct from one another but are simultaneously activated as parts of a cooperative unit (Meijers \& Hermans, 2018). Hubert Hermans and Agnieszka Hermans-Konopka (2010) argue that coalitions of conflicting or opposing positions have the potential to engender strong motivation, their effects surpassing those of individual positions taken separately.

During initial teacher education, the mechanism of 'coalition' can appear in educational situations that bring with them a tension between student teachers' positions of 'I as a student' and 'I as a teacher'. In this article, we have explored these two positions and the possibility of forging coalitions between them during the key learning experiences mentioned by the student teachers. 


\section{Key learning experiences during the process of positioning}

The Practicum in initial teacher education is a transition in(to) an educational institution, and it offers the student teachers 'key learning experiences' (KLE), representing their first opportunities to think and act as professionals. In broad terms perspective, KLEs are events that student teachers encounter during their studies that contribute to their learning. These KLE may be situated in different settings of teacher education, such as courses or teaching practice, can be both positive and negative and usually occur unexpectedly (Ahonen et al., 2015).

These events can often take the form of a 'crisis', in Meijer's (2017) terminology. A crisis appears when "a struggle is taking place, and this usually involves the development of a new part of your identity" (p. 214). This struggle in the context of the practicum could imply a negotiation between two overarching positions: I as student and I as teacher. In this article, we explore the dialogue between these two positions as they occur in different KLE that appear in the context of the Practicum. Placing students in a new social environment (e.g., a classroom) can be considered an experience, which in turn helps them shape a new position (e.g., I as a professional/I as a teacher). But this transition between positions is not an easy process, because it implies different types of tensions (Alsup, 2006; Leijen \& Kullasepp, 2013b; Pillen, Den Brok \& Beijaard, 2013). The findings revealed student teachers' tendency to maintain personal position(s) when managing tensions involving their values. These tensions that student teachers experience regarding their professional identity can sometimes prevent student teachers from successfully positioning themselves as teachers. The tensions can also make it difficult for them to see themselves as teachers and act as such, and, in consequence, can be an obstacle to the development of their professional identities as teachers (Alsup, 2006; Pillen et al., 2013). However, when the key learning experiences result from internally and intentionally orchestrated learning opportunities based on student behaviour, they can lead to profound changes in student professional identity (Ahonen et al., 2015).

The process of reflection about the emerging tensions is a useful training strategy and usually implies a 'repositioning' process (Meijers \& Hermans, 2018). Throughout this process, student teachers move from one position (that of a student or learner) to another (that of a teacher or professional). At other times, they combine these two positions in a 'coalition'. For example, student teachers might act as mere students when they observe the classroom teacher, but in other situations may position themselves as teachers, for example, by planning and making decisions autonomously when they are conducting a group 
of pupils. In addition, they may be repositioned by signs and messages communicated by others. For example, when mentors give them the autonomy to take decisions it is easier for them to position themselves as teachers.

Dialogue between positions can be facilitated by oral or written reflexion about meaningful or key learning experiences (Ahonen et al., 2015; Leijen \& Kullasepp, 2013a; Meijer, De Graaf \& Meirink, 2011). Hubert Hermans and Els Hermans-Jansen (1995) showed how the personal continuity of the self is assured by self-narration about meaningful experiences, which that are organized into a single structured narrative system.

In this study we have explored how student teachers perceived key learning experiences during their first practicum and how they positioned themselves when they tried to cope with these experiences.

\section{METHOD}

To achieve the general aim mentioned above, we have posed three specific questions:

Research question 1: What type of key learning experiences do student teachers identify during their first practicum?

Research question 2: What was the relationship between the different positions activated by student teachers and the KLEs they faced?

Research question 3: Which are the student teachers' repertories of positions?

\section{Context of the study}

This study was carried out at a Primary Teacher Education program in Spain. A degree program in teacher education at a Spanish university consists of four academic years. Out of a total of 240 ECTS (60 ECTS per year), a maximum of 60 ECTS corresponds to the practicum, in accordance with Spanish Ministry of Education (2014) requirements.

At the Faculty of Primary Education where the research was carried out, teaching practice accounts for a total of 38 ECTS, which are split into three different time periods. Traditionally, Practicum I (6 ECTS) takes place in the second year and is focused on classroom observation and the design of a short intervention. Practicum II (14 ECTS) is offered in the third year, with students responsible for planning and teaching a lesson. Finally, during Practicum III (18 ECTS), in the fourth and final year, students reflect about their professional identities as teachers and implement a long classroom intervention quite autonomously. 
This study was carried out during Practicum I. Within this practicum period, student teachers spend 120 hours at a school workplace under the supervision of a mentor, as well as 22 hours at the university participating in a seminar (1012 students) led by a lecturer. During Practicum I, the activities conducted in the university setting include researching scientific literature about certain topics, planning a brief intervention at the school and designing an interview with the school teacher. At the school, meanwhile, the activities include observing the educational needs of pupils and carrying out the brief intervention in the classroom.

\section{Participants}

Twenty-seven student-teachers ( 23 females and 4 males) with an average age of 21.5 years participated in the study. $88.8 \%$ were pursuing their first university degrees, whereas $11.1 \%$ possessed previous university or vocational degrees. We used non-probabilistic, convenience sampling given the two professors' interest in participating in this research project and the students' availability to participate voluntarily in the study. The sample was representative of student teachers as a whole in this context in terms of their gender, age, and student status, because the seminar groups are randomly assembled.

Each of the participants was enrolled in one of two seminar classes that lasted eleven sessions. The main objective of these sessions was to guide students in the design of a brief intervention in the practicum school and to encourage them to reflect on the key learning experiences that they experienced during this period. All of them were enrolled in the first practicum of the education program, and none reported having any prior teaching experience.

\section{Data collection}

Data were collected through a semi-structured interview at the end of the practicum seminar in May and June 2017. The first author contacted each of the participants via email and interviewed them in person in the university setting. The interviews were audio recorded and transcribed verbatim. The duration of these interviews was between 38 minutes and 1 hour. The aim of the interview was to collect student teachers' perceptions of the KLEs they had encountered during their teaching practice. The interviewer asked each participant to identify (and write on a sheet of paper) the names of 6-8 KLEs. After that, student teachers gave a brief description of each KLE, explained how they had acted to deal with each KLE and what they had learned from the experience. 


\section{Data analysis}

Data were analysed using qualitative content analysis (through MaxQda 2018). The iterative process of coding consisted of four steps. Firstly, we compiled all the KLEs reported by the participants in a single document. From this document, we selected the KLEs related to the student teachers' activity in the schools (for this analysis, we excluded the KLEs related to the university context). Twenty-two of the participants reported at least one KLE having occurred at the schools where they had done their teaching practice, but five reported only KLEs occurring at the university.

Secondly, we created an individual document for each KLE ( $n=108)$, and we categorized all of them in in terms of their content and according to with some prototypical problems of novice teachers noted by Simon Veenman (1984). Thirdly, we made a second-order categorization of the key learning experiences, categorizing all the statements again according to the kind of position the student teachers had activated with regard to each KLE: $a$ ) I as a student; or $b$ ) I as a teacher. Fourthly, in order to illustrate the repertoire of positions adopted by each participant, we created a document for each participant with the KLEs identified and the various positions that he/she had activated when facing each of them.

In order to assess the reliability of the categories and coding, two researchers analysed $30 \%$ of the data. The inter-rater agreement level was $81.82 \%$. The few questionable cases were discussed until a consensus was reached.

\section{RESULTS}

\section{Research question 1: What type of key learning experiences do student teachers identify during their first practicum?}

The total number of KLEs described by students was 108. Each student reported between two and eight KLE related to the school setting. Typically, student teachers described short events that had occurred during their teaching practice. The majority of the experienced described were positive (75\%). The students reported having learned useful lessons from these key experiences, or said that the experiences had been important in shaping their perceptions of teachers' work. Only in the KLE category of Conflicts between pre-existing conceptions and reality did participants report more negative than positive experiences as a result of their first confrontation with the real complexity of school classrooms. 
We have identified five types of KLE, according to their content. Table 1 shows the names of these categories, their frequency and the prevalence of positive and negative experiences within each.

\begin{tabular}{|c|c|c|c|}
\hline KLE & $n=108(\%)$ & Positive & Negative \\
\hline Classroom instruction $(\mathrm{Cl})$ & $29(26.85 \%)$ & 26 & 3 \\
\hline Socialization (S) & $25(23.15 \%)$ & 22 & 3 \\
\hline $\begin{array}{l}\text { Conflicts between pre-existing con- } \\
\text { ceptions and reality }(C R)\end{array}$ & $23(21.30 \%)$ & 11 & 12 \\
\hline Classroom management (CM) & $16(14.81 \%)$ & 9 & 7 \\
\hline Diversity of learners (D) & $15(13.89 \%)$ & 13 & 2 \\
\hline Total & 108 & 81 & 27 \\
\hline
\end{tabular}

Table 1. Number and percentage of KLE

\section{Classroom instruction}

This type of KLE was the most frequent in the student teachers' narrations (26.85\%). These experiences were related to the student teachers' knowledge of how to teach in the classroom and guide educational activities. Some of the KLEs reported by student teachers refer to a lack of confidence in their selfefficacy in when guiding or implementing their intervention in the classrooms, or to difficulties in planning and creating educational units to meet the needs of their pupils. However, the majority of the participants reported experiences of success in the KLEs in this category (26 of the 29 statements):

When I designed the activities, I took into account that they were significant for the pupils. And I saw that it would be when the students showed great interest and motivation in doing it. The pupils were happy. As a future teacher, it is important to learn to plan and design activities that motivate students and help them learn to the fullest." (Interviewed G2-06, p. i, June 2017')

1 In this study, participants have been coded to ensure their anonymity. Coding responds to: seminar/group 1: G1 or seminar/group 2: G2, the participant number: 01, 02, ...Example: G101; type of interview: personal interview (p.i), month and year. 


\section{Socialization}

This category of KLE involved the relationships (positive or otherwise) that the participants established with their mentors or other professionals at the schools, including the extent to which they were allowed to participate in teachers' meetings, as well as their relationships with other teachers and pupils. Twenty-five (23.15\%) KLEs related to the socialization of the student teachers in the schools were reported by the participants, twenty-two of them positive experiences. Nevertheless, some negative KLEs did affect student teachers' view of their roles as teachers, especially when school teachers did not treat them as equals but simply as unskilled assistants:

One day I went to another class. That day, they did an activity with water, and the classroom teacher said to me, 'Girl, you will mop up the water.' It made me feel very bad. She only thought of me as the intern and did not recognize me as a teacher. It was interesting to see the different ways the teachers in the school had of dealing with the teacher trainees. My mentor teacher considered me another teacher. (Interviewed G1-06, p.i, May 2017)

\section{Conflicting between pre-existing conceptions and the reality}

This type of KLE referred to the tension generated between personal convictions or expectations about teaching and the educational practices or the reality observed at the school. Student teachers reported $23(21.30 \%)$ cases of KLEs falling into this category. These preconceptions can be related both to the expectations that they have of their pupils and their learning abilities and to the way in which student teachers understand the processes of teaching and learning. Student teachers reported an equal number of positive and negative KLEs in this regard:

Because I think ... it's something I did not expect, I did not think 4th-grade children were going to come out with that reasoning. I did not expect that they would say that. Whether or not I liked it, I did not expect to them to come up with such an elaborate reflection. (Interviewed G2-13, p.i, June 2017)

Sometimes, they reported problems in reconciling the social realities of the schools and the school realities they had experienced when they were younger/pupils:

In my school, there were children with personal problems. Specifically, there was a 7-year-old boy whose father was in prison. Sometimes this child did not come to school because he had to take care of his younger siblings. One day, this child lost control and began screaming for help. I had never seen this. I never imagined that such small children could have 
so many problems. It's an educational context that I wasn't aware of but I needed to learn about. At that moment, I didn't know how to act. I cried when I saw this reality. (Interviewed G1-09, p.i, May 2017)

\section{Classroom management}

Another type of KLEs reported by the student teachers involved difficulties with classroom management $(14.81 \%)$. They reported not knowing how to prevent, deal with and improve pupils' behaviour problems in the classroom, such as the lack of silence and chaos. The student teachers expressed feelings of a lack of authority and an inability to impose limits and keep order in the classroom:

When I carried out my intervention, there was a time of great chaos. Pupils spoke all the time and I did not know how to control the situation. Knowing how to control a situation with students talking or an out-of-control class is important for me, because in the future if I am a teacher, I want pupils to respect me. Unfortunately, I was not able to learn control methods in these practices. (Interviewed G1-01, p.i, May 2017)

\section{Diversity of learners}

Student teachers reported 15 KLEs $(13.89 \%)$ related to challenges in dealing with students' differences and educational needs or in understanding and respecting the students' cultural, ethnic, racial, gender and religious diversity. However, the majority of the KLEs in this category reported by the student teachers were positive (13 statements).

Some of these KLEs referred to the lack of knowledge about how to address diversity in the classroom. Throughout their university training, the student teachers theoretically learn about inclusive methodologies that allow them to adapt educational activities to the range of educational needs that children can present in the classroom. For many of these students, being able to see these curricular adaptations in schools was important to their formation as teachers.

We have learned that the child should be placed at the centre of education, the teacher is the one who must adapt the educational activities to the child, not the other way around. It's something we had studied, but I did not know if it really took place in the schools, and I saw that in the school they really did implement these ideas. The educational activities were adapted to the needs of the child and not to what the teacher wanted. My teacher-mentor tried to give students materials that really helped them learn and reach the same level as their classmates. (Interviewed G203, p.i, June2017) 


\section{Research question 2: What was the relationship between the different positions activated by the student teachers and the KLEs they were facing?}

Placing students in a new social environment such as a school can act as a formative experience and give rise to a new position (e.g. teacher). When the student teachers faced the KLEs, they positioned themselves as students or as teachers, or they combined these two positions. Student teachers took different positions according to how they understood their role in the classroom. Table 2 shows how student teachers positioned themselves during each type of KLE.

\begin{tabular}{lcc}
\hline \multicolumn{1}{c}{ KLE } & $\begin{array}{l}\text { I as a student } \\
(\mathrm{n}=66 ; 61,1 \%)\end{array}$ & $\begin{array}{c}\text { I as a teacher } \\
(\mathrm{n}=42 ; 38,89 \%)\end{array}$ \\
\hline Classroom instruction & $8(12,12 \%)$ & $21(50 \%)$ \\
Socialization & $22(33,33 \%)$ & $3(7,14 \%)$ \\
$\begin{array}{l}\text { Conflicts between pre- } \\
\text { existing conceptions and } \\
\text { reality }\end{array}$ & $19(28,79 \%)$ & $4(9,52 \%)$ \\
$\begin{array}{l}\text { Classroom management } \\
\text { Diversity of learners }\end{array}$ & $7(10,61 \%)$ & $9(21,43 \%)$ \\
\hline
\end{tabular}

Table 2. Student teachers' positions with regard to the different types of KLE

Student teachers positioned themselves as students in more than $60 \%$ of the KLEs. When they adopt this position, they observe educational practices, and the strategies used by their mentors are accepted without any reservations. In these situations, student teachers did not tend to act, and they reported feeling that they needed to learn more in order to be able to decide on the best course of action. The KLEs that fell into the categories of Socialization and Conflicts between pre-existing conceptions and reality the times when student teachers were mostly likely to position themselves as students $(33.33 \%$ and $28.79 \%$, respectively).

In the other $38 \%$ of the KLEs, student teachers positioned themselves as teachers. In this type of KLE, the student teachers acted and made decisions with autonomy. They applied the theoretical knowledge acquired at the university to the school setting, or they adopted a position of equality to that of their 
mentors or other teachers at the school. This generally happened in the classroom instruction experiences $(50 \%)$ when they carried out the brief instruction they had designed or, when they attended teachers' meetings.

From our analysis, it follows that how student teachers position themselves may be influenced by a series of both external and internal conditions. For example, if the student teachers perceived themselves as isolated outsiders or lacked the confidence to act in a specific KLE, they usually positioned themselves as students. On some occasions, they felt that they did not belong to the educational community, and at other times they felt the need for more assessment or guidance from their mentors. Another condition that can influence is the level of knowledge about the school community or the educational needs of the pupils.

However, if student teachers perceived themselves as professionals, they usually adopted the teacher position. This occurred frequently when they were planning and making decisions while they conducted groups of pupils with autonomy. Also, they tended to position themselves as teachers especially when they had the opportunity to express their theoretical knowledge and to share it with other teachers at the school (e.g. when they attended teachers' meetings).

In the paragraphs below, we show examples of how they positioned themselves as students or as teachers in each of the KLEs that we have identified.

When faced with the classroom instruction KLEs, the student teachers mostly positioned themselves as teachers $(47.61 \%)$ when they led the instruction or when they made decisions with autonomy:

When I started teaching in the classroom, the teacher told me, "You are alone with the pupils." I felt good. I laughed with the children. They did have questions and I answered them. It was very easy. I felt that I was leading the group very well. That was when I thought, 'Maybe I'll be a good teacher.' (Interviewed G1-06, p.i, May 2017)

I did an activity in the class where the children had to work in pairs and one child did not come to school. I had to reorganize the groups so that everyone could do the activity. It was a moment of panic, but nobody knew because I was able to do it alone. (Interviewed G1-12, p.i, May 2017)

Nevertheless, in this type of KLE, the student teachers sometimes found it difficult to act as teachers when they were uncertain of how to approach and talk to the pupils:

We were doing a craft activity in class and the pupils were making a Sant Jordi card. There was a child whose card was very dirty and wrong. I said 
to him, 'It is a disaster, you can do it better.' It was full of blots. It was a moment of stress when I was helping other children and I don't know exactly how I said it to the pupil. I think I talked to him kindly, but the child took it very badly. He looked very angry, and I asked him, 'What's wrong? And he said, 'You told me I'm a disaster.' No, my God, I did not say this. For me, it was important because I learned how what you say to a child can affect them and that your opinion is very important to them. You are a model. (Interviewed G2-11, p.i, May 2017)

When student teachers discussed KLEs related to Socialization, we could clearly observe that they positioned themselves because they needed to learn about their schools' cultures and the pupils' educational needs:

We told her (the mentor) the three focus points, and she gave us her point of view, which was very interesting, and she gave us ... her opinion. We had only spent two days in the classroom and we did not know what the children were like. Her opinion was very important when I was designing my classroom intervention. The teacher helped me a lot, and she explained many things to me about the children and the school. I told her how I saw things and she helped me to see them in new ways. I was lucky that she gave me constant feedback. (Interviewed G1-05, p.i, May 2017)

Only when student teachers attended teachers' meetings did they adopt an equal relationship with the other teachers at the school, contributing their theoretical knowledge and opinions about the process of education. They described some situations during the teaching practice in which they were able to identify or apply some theoretical knowledge they had studied:

During the practice period, I was able to go to the teachers' meetings. It was for 5 or 6 days. At the University, I learned many theoretical concepts but, at the teachers' meetings, we also talked about many of these concepts. You could see how they adapted this theoretical knowledge to reality. It linked theory and practice. I participated in these teachers' meetings by giving my opinion. We were not just spectators. (Interviewed G1-05, p.i, May 2017)

When we analysed the statements related to the KLEs categorised as Conflicts between pre-existing conceptions and reality, we noted that most of the student teachers positioned themselves as students when they were exposed to surprising or unexpected situations (e.g. when they had been unaware of the social reality at the school):

I was at a school located in a troubled neighbourhood with a lot of immigration. One day when I got to class my mentor was scolding a student. This student, the day before, had beaten up another student just because he was an immigrant. It was a reality that struck me. I did not expect such 
younger children to act like that. I noticed how the teacher talked with the child and what he said to him. (Interviewed G2-09, p.i, June 2017)

Student teachers positioned themselves as teachers when they had to regulate their actions or decisions in order to adapt them to the context:

I designed an activity that I thought the pupils... not that they wouldn't be able to do it but that it would be hard for them. But I saw that it wasn't when I corrected the activities and saw that they had known how to do it. It was important because I think that you shouldn't underestimate the abilities of children. I learned to value, to believe in students. (Interviewed G2-07, p.i, June 2017)

The participants in this study reported facing fewer KLEs as students than as teachers in their Classroom management experiences. In most cases, student teachers positioned themselves as students when they felt they lacked authority or confidence in their abilities. In some case, they expressed the need to be close to their pupils:

I feel very close to the students but one day a student took a necklace and started playing with it and asking questions about my personal life without paying attention to the activities we were doing. And I did not know what to do. I have no authority. It's very hard for me. (Interviewed G1-12, p.i, May 2017)

Sometimes when student teachers saw pupils behaving poorly or disrespecting one another, they adopted positions as teachers as they attempted to reflect with pupils about the situation:

The treatment among the students was very bad. They insulted one another and exchanged racist words. I was very angry. When I saw that, I began to talk to pupils about respect. The students listened to me and stopped insulting one another. (Interviewed G1-11, p.i, May 2017)

In relation to the Diversity of learners KLEs, student teachers adopted positions as students when they did not agree with their mentors' actions:

In my class, there was a child with attention problems. We were doing a writing activity, and this child was bothering others a lot, and while everyone was doing the writing activity, the teacher gave him another assignment so that he would not disturb the class and to calm him down. I asked the mentor teacher why he was doing this and he answered that they wanted him to be silent. I saw someone being excluded, and I was very sad to see that the child was not being included, especially when he had the skills to do the activity. I could not do anything either, I was there as an observer. I did not like seeing this (Interviewed G2-12, p.i, May 2017) 
However, some participants adopted positions as teachers when they were designing an inclusive lesson:

In my class, there was a lot of diversity. I had never seen this before. I chose this class because the teachers told me that there were a lot of children with learning or behavioural difficulties, and I was interested in learning learn how to teach these children. When I designed the intervention, I considered these children and did group activities so they could help each other. When we did these activities in class, I went from group to group and helped them so that everyone could do it (Interviewed G1-12, p.i, May 2017)

\section{Research question 3: Which are the student teachers positions repertories?}

Table 3 shows how each participant positioned himself in each of the KLE that they mentioned. From the analysis of the data, we were able to identify three repertoires of positions of student teachers according to the positioning that they adopted in the KLEs reported.

Repertoire of Positions 1: I as a student teacher (18.18\%)

Four participants (Interviewed G1-01, p.i, May, 2017; Interviewed G1-04, p.i, May 2017; Interviewed G2-13, p.i, June, 2017; and Interviewed G2-14, p.i, June 2017) positioned themselves as students in all the KLE they reported. These narratives seem to have some common aspects that could influence the way they generally positioned themselves. One of these aspects was the lack of self-confidence in their own abilities to conduct their brief instructional activity. Some also expressed feelings of insecurity. In some cases, they said that they did not have enough information about the characteristics and educational needs of the students and that the mentors had not given it to them. Another common aspect recounted by these participants was that they felt the need to control all aspects of the educational process and had not been aware of how unforeseen circumstances can emerge in the classroom.

Repertoire of Positions 2: I as a teacher (4.55\%)

Only one student teacher (Interviewed G2-05, p.i, June, 2017) positioned herself as a teacher in all the KLE reported for him. In this case, the student showed a great degree of involvement in all the actions she took in the school setting in the school setting, as well as displaying a high level of autonomy when making decisions about how to act in the school. She conducted an indepth analysis of all the mentor's actions, and she applied what she had learned from her observation when she conducted the group of pupils.

Repertoire of Positions 13: Hybrid position (77.27\%). 
The majority of participants positioned themselves both as students and as teachers, depending on the kind of KLE reported. However, the participants in this profile did not present the same number of KLEs for each position. While three of the participants (17.64\%) did position themselves the same number of times in the two positions (Interviewed G1-03, p.i, May, 2017; Interviewed G209, p.i, May, 2017; and Interviewed G2-12, p.i, May, 2017), 54.94\% of the student teachers positioned themselves as students more often than as teachers. As we can see in Table 3, for the KLEs related to Socialization the participants the participants were more likely to position themselves as students, while in the Classroom Instruction KLEs they positioned themselves as teachers the most often. Only five $(29.41 \%)$ student teachers presented adopted the position of teachers more often than that of students in the KLEs they cited. Those who did so positioned themselves as teachers most often in the KLEs related to Classroom management.

On some occasions, in the same type of KLE, the student teachers positioned themselves sometimes as teachers and others as students. When this happened, we have considered the positions to be in coalition with one another, meaning that the student teachers were engaged in a process of positioning or repositioning themselves with regard to this kind of KLE.

In this sense, six students displayed a coalition of positions in the KLEs related to Classroom instruction; three for the KLEs connected to Socialization and the same number for those related to Diversity of learners, and only two for Conflicts between pre-existing conceptions and reality experiences. No student was observed to have a coalition of positions when it came to Classroom management experiences. We have shaded the rows where coalitions appeared in Table 3. It seems that the KLE type does not determine the way students position themselves. Rather, it seems that student teachers tend to adopt positions as teachers when they gain confidence in their skills as teachers throughout their practicum period, or when their mentors provide positive feedback on their actions.

An interesting result was the case of Interviewed, G2-12, p.i, May, 2017; who adopted both kinds of positions in all the KLEs she reported. She recounted in one KLE that her mother is a teacher and that, probably, she has more knowledge than some others about the profession or about how to act as a teacher. So, for example, in the Diversity of learners KLE, she positioned herself as a student when she saw how her mentor conducted a group of pupils including one child with autism:

In my class, there was a child with autism. One day, the teacher proposed to the pupils some mathematical games where they had to think very fast. 
The child with autism could not think so fast, and I saw how the teacher adapted the games so he could do them. I also had to adapt my activities to that child but I did not know how to do it. However, his classmates helped him and he was able to do the activities. (Interviewed, G2-12, p.i, May, 2017 as a student)

\begin{tabular}{|c|c|c|c|c|c|c|c|c|c|c|c|}
\hline \multirow[b]{2}{*}{ Interviewed } & \multicolumn{5}{|c|}{ I as a teacher } & \multicolumn{5}{|c|}{ I as a student } & \multirow[t]{2}{*}{$\begin{array}{c}\text { Total } \\
\text { KLE }\end{array}$} \\
\hline & $\mathrm{Cl}$ & $S$ & $\mathrm{RC}$ & CM & $\mathrm{D}$ & $\mathrm{Cl}$ & $S$ & $\mathrm{RC}$ & CM & D & \\
\hline G1-01, p.i, May 2017 & & & & & & 1 & & & 1 & & 2 \\
\hline G1-02, p.i, May, 2017 & 1 & 1 & 1 & & & & 2 & & 3 & & 8 \\
\hline G1-03, p.i, May 2017 & 1 & & & & & & & & & 1 & 2 \\
\hline G1-04, p.i, May 2017 & & & & & & & & 1 & & 1 & 2 \\
\hline G1-05, p.i, May 2017 & & 1 & & 2 & & & 1 & & & & 4 \\
\hline G1-06, p.i, May 2017 & & 1 & 1 & 2 & 1 & & 2 & & & & 7 \\
\hline G1-08, p.i, May 2017 & 2 & & & 2 & & & & 2 & & & 6 \\
\hline G1-09, p.i, May 2017 & & & 1 & & & & 1 & 2 & & 1 & 5 \\
\hline G1-10, p.i, May 2017 & 1 & & & & & & 5 & & 1 & & 6 \\
\hline G1-11, p.i, May 2017 & & & & 2 & & 1 & 1 & 1 & & & 5 \\
\hline G1-12, p.i, May 2017 & 2 & & & & 1 & & 1 & 2 & & 1 & 7 \\
\hline G2-01, p.i, May 2017 & 1 & & & & 1 & 1 & 2 & & & & 5 \\
\hline G2-03, p.i, June 2017 & 1 & & & & & 1 & 1 & & & 1 & 4 \\
\hline G2-04, p.i, May 2017 & 1 & & & & & 1 & 4 & & 1 & & 7 \\
\hline G2-05, p.i, June 2017 & 1 & & & 2 & 1 & & & & & & 4 \\
\hline G2-06, p.i, June 2017 & 2 & & & & & 1 & & & & & 3 \\
\hline G2-07, p.i, June 2017 & 2 & & & & & & 2 & 3 & 1 & & 8 \\
\hline G2-09, p.i, May 2017 & 1 & & & & 1 & & & 1 & & 1 & 4 \\
\hline G2-11, p.i, May 2017 & 3 & & & & & 1 & & 1 & & & 4 \\
\hline G2-12, p.i, May 2017 & 1 & & 1 & & 2 & 1 & & 1 & & 2 & 8 \\
\hline G2-13, p.i, June 2017 & & & & & & 1 & 1 & 1 & & & 3 \\
\hline G2-14, p.i, June 2017 & & & & & & 1 & 2 & & & & 3 \\
\hline TOTAL & 20 & 3 & 4 & 10 & 7 & 8 & 22 & 19 & 7 & 8 & 108 \\
\hline
\end{tabular}

Table 3. Type and number of KLE for each participant and the type of position adopted

However, she acted as a teacher when she carried out her intervention in the classroom:

There was another child in the class with some type of ADHD. The first day, the school principal told me, 'Be careful this child.' When I did my inter- 
vention, the mentor asked me if I wanted to take this child out of class because he would disturb the other pupils. I said no. The first time I did the class, he behaved badly. I talked to the boy and changed his seat. After that, he behaved well and did the activities. As a teacher, you must learn to deal with children like that. (Interviewed, G2-12, p.i, May, 2017)

\section{DISCUSSION AND CONCLUSIONS}

The aim of this study was to identify the KLEs that occurred during the first practicum of a group of student teachers and to determine how and why they positioned themselves with respect to these experiences and why they adopted these positions.

Related to the first research question, the types of KLEs reported by the participants in this study were Classroom Instruction, Socialization, Conflicts between pre-existing conceptions and reality, Classroom management, and Diversity of students, a list that reflected some of the most prototypical problems of novice teachers. The results of our study are in line with previous studies about beginning teachers in terms of how they cope with their first years of teaching and of the prototypical they face (see, for example Correa, MartínezArbelaiz, \& Aberasturi-Apraiz, 2015; Dicke, Elling, Schmeck, \& Leutner, 2015; Farrell, 2016; Veenman, 1984). Unlike these studies, our results showed that Socialization and Classroom instruction were the most frequently reported kinds of KLEs, while the prototypical problems of beginning teachers usually tend to be more connected to Classroom management and Diversity of learners. Thus, the students explained that the interaction with the educational community (teachers, students) generated great learning situations for them, and they said that these situations were only viewed as negative when the mentor failed to give the type of feedback that they expected. On the other hand, our students clearly positioned themselves as future teachers when they designed or implemented their classroom interventions.

Although some previous studies have dealt with the use of the reflections about KLEs in the development of teachers' professional identities (Ahonet et al., 2015; Meijer, 2017), the literature about what KLEs pre-service teachers have to cope with during in the practicum is scarce. However, research by Christina Gray, Peter Wright \& Robin Pascoe (2017) has highlighted how some situations that pre-service teachers are exposed to during their practicum period, such as a lack of knowledge about pupils' background or school policy, are stressful for them. The results of this study corroborate these results and show the difficulty that student teachers have in adopting positions as teachers if they lack sufficient information about the classroom context or the community. 
Our study defined five types of experiences that students tended to identify as keys to their learning processes as future teachers. The systematic reflection of these key learning experiences should be introduced into initial teacher education programs. Future teachers should learn about the best ways to act in different situations attending with regard to classroom instruction or management, socialization and learning personalization, always attending to the conditions of the particular context in which they are carried out.

The results with respect to our second research question show how the transition from a student teacher position to acting and thinking autonomously as a teacher is not an easy journey (Dang, 2013, Izadinia, 2016). The emotional impact of some of the experiences involved is called "reality shock" (Correa et al., 2015; Veenman, 1984). In other words, the development of teachers' identities is a process of negotiation between different positions taken during their initial training and, especially, during the practicum (Allen \& Wright, 2014; Körkkö, et al., 2016). Experiences that student teachers have in the practicum period influences how preservice teachers see themselves as future teachers (Beijaard et al., 2004).

In order to analyse the student teachers' positions with respect to the different KLEs, we have considered two general positions that are usually present in dialogue with one another during a teaching practicum: I as a student and I as a teacher. A KLE is a challenge that forces the student to move from the position of a student to that of a teacher (Ahonen et al., 2015; Meijer, 2017).

In this study, our results showed that the participants positioned themselves mostly as students in all the KLEs reported, as they faced difficulties in viewing themselves as future teachers. This can be explained by the fact that our sample was made up of second-year students who, prior to this practicum, had not done any internships in schools.

Student teachers were most likely to position themselves as students more frequently in the KLEs related to Socialization and Conflicts between pre-existing conceptions and reality. In these experiences, students tended to position themselves as observers of educational situations that they identified as important, but they displayed insecurities and uncertainties about how to deal with these situations autonomously and without the advice of their mentors, sometimes expressing concerns that they did not have sufficient knowledge.

Our data point to some ideas about the conditions that might influence the transition from the position of a student to that of a teacher. For example, in the KLEs mentioned above, the participants sometimes felt like intruders in the schools because they were unfamiliar with the schools' social context, norms 
and culture. They were also often unsure of their own roles in the school setting, uncertain of how to act and of the mentors' expectations (Gray et al., 2017). In these cases, mentors should play an important role in introducing the student teacher to the school culture, providing them with the information they need. In some cases, the tensions that we can observe in these KLEs could be related to those observed by Alsup (2006), and they could be caused by the collision between student teachers' personal convictions about teaching and the harsh and rude reality of everyday classroom life.

Another condition that could complicate the transition to a position as a teacher is a lack of a trusting relationship between student teachers and their mentors, especially in terms of the feedback given by mentors. Research shows that student teachers primarily expect their mentors to offer them instructional and emotional support (Becker, Waldis \& Staub, 2019). Mentors and other teachers at the schools represent the profession, and they should help student teachers in the socialization processes that will allow them to join the field (Izadinia, 2018). When student teachers arrive at the schools that will host their practicum periods, they are unfamiliar with the school culture, what the pupils are like and their educational needs, and what is expected of them. Thus, it is important to establish a strong relationship between mentor and student teacher. If the mentors treat them as mere interns and do not include them in the educational community as equals, student teachers could face difficulties in assuming positions as teachers. Meanwhile, the feelings of isolation reported by some participants in this study can damage their sense of belonging as professionals, as shown in studies by Farrell (2016) of novice teachers and by Bloomfield (2010) of pre-service teachers. Research shows how the relationships that student teachers establish with their mentors in the practicum allow them to share an understanding of their roles, responsibilities and expectations, as well as the different positions taken by student teachers during the practicum period (Trent, 2013).

Additionally, we know that mentors' feedback affects student teachers' beliefs about their self-efficacy (Lamote \& Engel, 2010). During the practicum, the students in this study received continuous support in the planning of their short classroom interventions, and likely made students more likely to position themselves as teachers in the classroom instruction experiences that they recounted to us.

Finally, with regard to the third research question, our results allow us to identify three different repertoires of positions. The most interesting is the hybrid position, where we can observe how student teachers moved between the position of a student and that of a teacher. In some KLEs, there seems to be a dia- 
logue between positions. In these cases, we have concluded that a coalition is at work. This represents a natural mechanism whereby student teachers are trying to develop their identities as teachers (Meijer \& Hermans, 2018).

Relations between different positions have implications for the development of a self-image as a teacher and, therefore for the construction of the professional identity of student teachers. Feeling like a teacher means acknowledging oneself as competent and self-efficient in school settings and as having the necessary skills to practice the profession. Thus, it was only in the KLEs where the student teachers had enough confidence in their skills or where mentors provided them with positive feedback that they were able to act as teachers (Mena, Hennissen \& Loughran, 2017). This very issue would be an interesting topic for future studies, which could analyze how the type of feedback received by the mentor in each of the five key learning experiences identified can influence the positioning process.

In short, this study highlights the need for both teacher educators and mentors to be aware of the KLEs that students report and the difficulties that student teachers face, all in order to give them the support and guidance they need to develop their positions as teachers in the context of the practicum. Moreover, this study has yielded interesting results that have contributed both to the creation of knowledge about the types of prototypical KLEs that student teachers face in the practicum and to an initial approach to the subject that will allow future research into how these KLEs affect the development of professional teacher identity.

\section{Educational implications}

One implication of this study is that useful information can be gained by examining students' reflections through the analysis of how they positioned themselves with regard to key learning experiences. A metacognition position could also facilitate greater awareness of how they position themselves during different key experiences and of their perception of self-efficacy in each of them.

Another implication of this study is need to prepare school mentors (Becker et al., 2019). Theirs was a 'voice' that students usually evoke in their narratives. Currently, in our Catalan context, mentors don't have any training in how to carry out their functions, and we know that their supervision is important to the development of teachers' identities (Allas, R.; Leijen, A. \& Toom, 2016). Student teachers need to feel welcome in the educational community of reference and to know that they will be treated as equals. Therefore, the mentors at the school must provide a climate of confidence and security that allows 
student teachers to apply all the theoretical knowledge learned at the university to the classroom.

\section{Limitations}

Firstly, the sample is too small to be able to generalize the results obtained. However, these results coincide with the literature reviewed, where beginning teachers report similar prototypical problems. Secondly, we believe that it is necessary to carry out future longitudinal investigations in order to investigate the extent to which these prototypical problems are repeated in subsequent practicums.

\section{REFERENCES}

Ahonen, Elsi; Pyhältö, Kirsi; Pietarinen, Janne, \& Soini, Tiina (2015). Student teachers' key learning experiences-Mapping the steps for becoming a professional teacher. International Journal of Higher Education, 4(1), 151-165. https://doi.org/ 10.5430/ijhe.v4n1p151

Akkerman, Susanne, \& Meijer, Pauline. (2011). A dialogical approach to conceptualizing teacher identity. Teaching and Teacher Education, 27(2), 308-319.

https://doi.org/10.1016/j.tate.2010.08.013

Allen, Jeanne, \& Wright, Suzie. (2014). Integrating theory and practice in the preservice teacher education practicum. Teachers and Teaching, 20(2), 136-151. https://doi.org/10.1080/13540602.2013.848568

Allas, Raili; Leijen, Äli, \& Toom, Auli. (2016): Supporting the Construction of Teacher's Practical Knowledge Through Different Interactive Formats of Oral Reflection and Written Reflection. Scandinavian Journal of Educational Research,61(5), 600-615. https: //doi.org/10.1080/00313831.2016.1172504

Alsup, Janet. (2006). Teacher identity discourses: Negotiating personal and professional spaces. New York: Routledge.

Becker, Eva; Waldis, Monica, \& Staub, Fritz. (2019) Advancing student teachers' learning in the teaching practicum through Content-Focused Coaching: A field experiment. Teaching and Teacher Education. 83, 12-26.

https://doi.org/10.1016/j.tate.2019.03.007

Beijaard, Douwe; Meijer, Pauline, \& Verloop, Nico. (2004) Reconsidering research on teachers' professional identity. Teaching and Teacher Education, 20, 107-128. https://doi.org/10.1016/j.tate.2003.07.001

Bloomfield, Di. (2010) Emotions and 'getting by': a pre-service teacher navigating professional experience. Asia-Pacific Journal of Teacher Education, 38(3), 221-234. https://doi.org/10.1080/1359866X.2010.494005

Colliander, Helen. (2018) The experienced newcomer - The (trans)forming of professional teacher identity in a new landscape of practice. Teaching and Teacher Education, 69, 168-176. https:// doi.org/10.1016/j.tate.2017.10012 
Correa, José Miguel; Martínez-Arbelaiz, Asunción, \& Aberasturi-Apraiz, Estibaliz. (2015). Post-modern reality shock: Beginning teachers as sojourners in communities of practice. Teaching and Teacher Education, 48, 66-74. https://doi.org/10.1016/j.tate.2015.02.007

Dang, Thi Kim Anh. (2013). Identity in activity: Examining teacher professional identity formation in the paired-placement of student teachers. Teaching and Teacher Education, 30, 47-59. https://doi.org/10.1016/j.tate.2012.10.006

Dicke, Theresa; Elling, Jill; Schmeck, Annett, \& Leutner, Detlev. (2015). Reducing reality shock: The effects of classroom management skills training on beginning teachers. Teaching and Teacher Education, 48, 1-12.

https://doi.org/10.1016/j.tate.2015.01.013

Farrell, Thomas. (2016). Surviving the transition shock in the first year of teaching through reflective practice. System, 61, 12-19. https://doi.org/10.1016/j.system.2016.07.005

Gray, Christina; Wright, Peter, \& Pascoe, Robin. (2017) There's a lot to learn about a drama teacher: Pre-service drama teacher' experience of stress and vulnerability during an extend practicum. Teaching and Teacher Education, 67, 270-277. https://doi.org/10.1016/j.tate.2017.06.015

Hermans, Hubert. (2001). The Dialogical Self: Toward a Theory of Personal and Cultural Positioning. Culture \& Psychology, 7(3), 243-281. https://doi.org/10.1177/1354067x0173001

Hermans, Hubert, \& Gieser, Thorsten. (2012). Handbook of dialogical self theory. Cambridge: Cambridge University Press. https://doi.org/10.1017/CB09781139030434

Hermans, Hubert, \& Hermans-Jansen, Els. (1995). Self-narratives: The construction of meaning in psychotherapy. New York, NY, \& London, UK: Guilford.

Hermans, Hubert, \& Hermans-Konopka, Agnieszka. (2010). Dialogical self theory: positioning and counter-positioning in a globalizing society. Cambridge, UK: Cambridge University Press.

Izadinia, Mahsa. (2016). Student teachers' and mentor teachers' perceptions and expectations of a mentoring relationship: do they match or clash? Professional Development in Education, 42(3), 387-402. https://doi.org/10.1080/19415257.2014.994136

Izadinia, Mahsa. (2018). Mentor Teachers. Contributions to the Development of Preservice Teachers' Identity. In Paul A. Schutz, Ji Hong \& Dionne Cross Francis, (Eds.), Research on Teacher Identity (pp.109-119). Cham: Springer.

Körkkö, Minna; Kyrö-Ämmälä, Outi, \& Turunen, Tuija. (2016). Professional development through reflection in teacher education. Teaching and teacher education, 55, 198-206. https: //doi.org/10.1016/j.tate.2016.01.014

Lamote, Carl, \& Engels, Nadine. (2010). The development of student teachers' professional identity. European Journal of Teacher Education, 33(1), 3-18. https://doi.org/10.1080/02619760903457735

Leijen, Äli, \& Kullasepp, Katrin. (2013a). All roads lead to Rome: developmental trajectories of student teachers' professional and personal identity development. jour- 
nal of constructivist psychology, 26(2), 104-114. https://doi.org/https://doi.org/10.1080/10720537.2013.759023

Leijen, Äli, \& Kullasepp, Katrin. (2013b). Unlocking the potential of conflicts: a pilot study of professional identity development facilitation during initial teacher education. International Journal for Dialogical Science, 7(1), 67-86.

Leijen, Äli; Kullasepp, Katrin. \& Ots, Aivar. (2013). The evaluation of internalisation of Teachers' Professional Role among Pre-Service Teachers. Estonian Journal of Education, 1, 72-96.

Linell, Per. (2009). Rethinking Language, Mind, and World Dialogically. New York: Information Age Pub Inc.

Meijer, Pauline. (2017). Essential Issues in Developing a Professional Identity as a Teacher. In Xudong Zhu, A. Lin Goodwin \& Huajun Zhang (Eds.), Quality of Teacher Education and Learning. Theory and Practice (pp. 207-223) Singapore: Springer.

Meijer, Pauline; De Graaf, Gitta, \& Meirink, Jacobiene. (2011). Key experiences in student teachers' development. Teachers and Teaching: theory and practice, 17(1), 115-129. https://doi.org/10.1080/13540602.2011.538502

Meijers, Frans, \& Hermans, Hubert. (2018). Dialogical self theory in education: an introduction. In Frans Meijers, \& Hubert Hermans (Eds.), The dialogical self theory in education (pp. 1-17). New York: Springer.

Mena, Juanjo; Hennissen, Paul, \& Loughran, John. (2016). Developing pre-service teachers' professional knowledge of teaching. The influence of mentoring. Teaching and Teacher Education, 66, 1-13. https://doi.org/10.1016/j.tate.2017.03.024

Monereo, Carles. (2019). The role of critical incidents in the dialogical construction of the identity of the teacher. Analysis of a case of professional transition. Learning, Culture \& Social Interaction, 20, 4-13. https://doi.org/10.1016/j.lcsi.2017.10.002

Pillen, Marieke; Den Brok, Perry, \& Beijaard, Douwe. (2013). Profiles and change in beginning teachers' professional identity tensions. Teaching and Teacher Education, 34, 86-97. https://doi.org/10.1016/j.tate.2013.01.003

Raggatt, Peter. (2015). Positioning: dialogical voice in mind and culture. Theory $\&$ psychology, 25(6), 775-797. https://doi.org/10.1177/0959354315590850

Sisson, Jaime. (2016). The significance of critical incidents and voice to identity and agency. Teachers and Teaching, 22(6), 670- 682. https://doi.org/10.1080/13540602.2016.1158956

Trent, John. (2013). From learner to teacher: Practice, language, and identity in a teaching practicum. Asia-Pacific Journal of Teacher Education, 41(4), 426440.https://doi.org/10.1080/1359866x.2013.838621

Toompalu, Aivi; Leijen, Äli, \& Kullasepp, Katrin. (2016). Professional role expectations and related feelings when solving pedagogical dilemmas: a comparison of pre- and in-service teachers. Teacher Development: An international journal of teachers' professional development, 21(3). https://doi.org/10.1080/13664530.2016.1237985

Veenman, Simon. (1984). Perceived problems of beginning teachers. Review of Education of Research, 54(2), 143-178. Htpps://doi.org/10.3102/00346543054002143 


\section{MIREYA GIRALT-ROMEU}

PhD student and assistant researcher of the University of Ramon Llull. She works as a Psychopedagogical Advisor of the Counselling and Psychological Innovation Service of Ramon Llull University. Her current research interests include the teacher professional identity development and, teacher-inquirer identity.

mireiagr3@blanquerna.url.edu

https://orcid.org/0000-0003-0097-4457

\section{EVA LIESA HERNÁNDEZ}

Assistant professor at the Department of Psychology of the University of Ramon Llull (URL). Coordinator of the Centre in Educational Innovation in the Faculty of Psychology, Educational Sciences, and Sports Blanquerna (URL). Her main areas of research are dialogical self-theory (DST), initial and continuous teacher education, teacher identity, and teacher-inquirer identity.

evalh@blanquerna.url.edu

https://orcid.org/0000-0002-9533-3689

\section{PAULA MAYORAL SERRAT}

PhD in Educational Psychology, associate professor and Coordinator of the Education Practicum in Teacher Degrees at FPCEE Blanquerna and senior researcher at the Interuniversity Research Group SINTE. Her current research interests include the development of the inquirer-teacher identity, practicum and teaching and learning processes in higher education and compulsory education.

mariapaulams@blanquerna.url.edu

https://orcid.org/0000-0002-8667-0560

\section{LORENA BECERRIL BALÍN}

Research scientist \& associate professor in Departament of Psychology and Educational Sciences in Open University of Catalonia (Barcelona). Psychopedagogical Advisor of the Counselling and Psychological Innovation Service (SAIP) of Faculty of Psychology, Educational Sciences and Sports, Blanquerna. Her research topics are teacher inquiry identity and initial and continous teacher education.

lbecerril@ouc.edu

https://orcid.org/0000-0001-6357-1300

\section{ACKNOWLEDGEMENTS}

This study was supported by the AGAUR (grant number 2018 FI_B1 000173) and the Faculty of Psychology and Educational Sciences Blanquerna (APR-FPCEE1819/02). 


\section{FORMATO DE CITACIÓN}

Giralt-Romeu, Mireya; Liesa Hernández, Eva; Mayoral Serrat, Paula \& Becerril Balín, Lorena (2020).Student teachers' positioning with regard to their key learning experiences in the first practicum. Quaderns de Psicologia, 22(2), e1570.

http://dx.doi.org/10.5565/rev/qpsicologia. 1570

HISTORIA EDITORIAL

Recibido: 16-09-2019

$1^{\text {a }}$ revisión: $30-04-2020$

Aceptado: 07-05-2020

Publicado: $31-08-2020$ 